\title{
New Enviromental Friendly Initiatives in the Production of Melomas (Citrus Grandis) in Kuala Kangsar, Perak, Malaysia
}

\author{
Salmizi Saad ${ }^{1}$, Muhammad Hafidz Abdul Raman ${ }^{1}$, Azizan Asmuni ${ }^{1}$, Khairuddin Idris ${ }^{1}$, Norsida Man ${ }^{1}$, Zabri Abd. \\ Wahid $^{2} \&$ Mahamud Shahid ${ }^{3}$ \\ ${ }^{1}$ Universiti Putra Malaysia, Malaysia \\ ${ }^{2}$ MARDI Perak, Malaysia \\ ${ }^{3}$ MARDI Headquarters, Malaysia \\ Correspondence: Salmizi bin Saad, Research Officer, Pejabat Pengarah MARDI Negeri Perak, 33000 Kuala \\ Kangsar, Perak Darul Ridzuan. Malaysia. Tel: 60-9-348-6715. E-mail: salmizi@mardi.gov.my
}

Received: May 13, 2013

doi:10.5539/ijbm.v9n1p180
Accepted: November 12, 2013 Online Published: December 18, 2013

URL: http://dx.doi.org/10.5539/ijbm.v9n1p180

\begin{abstract}
'Melomas', a new pomelo clone (Citrus grandis) was introduced to the public in 1998 by Malaysian Agricultural Research and Development Institute (MARDI). Several pilot projects involving the planting of Melomas were conducted to further promote this pomelo clone. One of these projects was conducted in Stesen MARDI Kuala Kangsar, Perak and as a result, healthy and vigorous pomelo trees were grown. In 2007, the pomelo trees managed to produce an abundance of flowers, but surprisingly the fruit setting had died and almost no harvesting was done. A very low harvest was reported due to an occurrence of fungus in numerous locations in Northern Perak in 2007 and 2008. A study was conducted beginning from January 2007 to December 2011 to tackle this phenomenon. It was noticed that every flowering season coincided with high daily rainfalls. The relatively high humid conditions had increased the incidence of Anthracnose infection that caused the young flower bud to die and undeveloped fruit sets to drop unattainably. The heavy rainfall severely prolongs raindrop smears on the flower fruit set. Almost every Melomas grower faced the same predicament. This case study was designed to intervene and stop the causal fungus infection brought by the rain. Transparent plastic covers (TPC) were introduced to prevent raindrops from continuously smearing the flower bunch. It was stapled onto the branch above the bunch of flowers to form small half cylinder plastic roofing that prevents the raindrop falling onto the small fruits. To tackle the problem, a series of workshops, technology transfer activities and extension programme were arranged for the Melomas growers by the MARDI and other government agencies in Perak. The results showed that the manipulation of the microenvironment around the flowers had helped the grower to recover and eventually increase the Melomas yield. It was observed that this low-cost technique had significantly increased the number of Melomas fruit sets as opposed to the control treatment (without plastic covers). This technique had been practiced by local pomelo farmers in Padang Rengas, spanning over an area of 35 ha and it is being practiced in a pilot project at MARDI Kuala Kangsar. It has a proven $85 \%$ success rate and has been reported to significantly boost the productivity in the area.
\end{abstract}

Keyword: Pomelo flower, manipulation of microenvironment, technology transfer, farmers

\section{Introduction}

'Melomas' was declared by MARDI in October 1998 to the local farm operators, as an alternative for grapefruit, mandarin, and orange. Special distinctive features of the fruit are it's simple fruit size of about 1.0-1.5 kg, rounded shape, thin skin, fill in the pink, juicy, sweet, fragrant smell, no astringent taste of its juice sac, and resistant to stem betel platter, Phytopthora parasitica (Mohd. Shamsudin et al., 2010). This has made the Melomas clone a popular choice for cultivation by pomelo farmers in Perak. MARDI took the initiative to advance further development of this Melomas clone through a few pilot projects in Perak (Mohamad Bahagia et al, 2008). One of the projects was conducted in Stesen MARDI Kuala Kangsar, Perak. Over 200 hectares were planted and cultivated with Melomas in Kuala Kangsar alone since 1998. Later in 2010, the area was reduced to 167 hectares with only 31.7 percent planted with pomelo that could produce $637.2 \mathrm{mt}(12 \mathrm{mt} / \mathrm{hectares})$ with a total yield value worth only RM 2.1 million (MOA, 2010). Furthermore, recent reports had warned farmers on price uncertainties 
of Melomas where the price had decreased to the lower range of RM1.60 per kilogram (Sinar Harian, 2012).

In 2007, the pomelo growers produced an abundance of flowers, but surprisingly the fruit sets died and almost no harvesting occurred. It was reported that the low harvest was due to an occurrence of fungi in various locations in Northern Perak from 2007 to 2008. Two areas severely hit were Padang Rengas and Kg. Perlop in Sg. Siput. This phenomenon was due to high daily rainfalls throughout every flowering season. The relatively high humid conditions had increased the incidence of Anthrachnose infection that made the flowers die out and the undeveloped fruit sets to drop off. However heavy rainfall (prolong raindrops) was the main reason that caused the fruits to drop. Almost every Melomas grower faced the same problem.

A case study was conducted beginning January 2007 to December 2011 to study this problem. Many growers had abandoned their fruit farms during this time and left it idle with unmanaged pomelo trees. MARDI realized that this problem might affect the overall productivity of pomelo production in Perak. Thus, a serious intervention, an innovation twist in farming practice and management, and an extension-training program was developed to revive the production of Melomas. An effort was made to restore some of the abandoned Melomas areas through updating the knowledge of farm operators on pruning, fertilizing and weed control. This effort was undertaken with the involvement and cooperation of MARDI, Federal Agricultural Marketing Authority (FAMA), and the Department of Agriculture (DOA), which was responsible for the pilot project. The objectives of this study are to develop a control mechanism for disease and infections of Melomas tress during the rainy season through new initiatives in technology application and to determine the impact of that technology application for its sustainability and the production of Melomas in the farms.

\section{The Phenomenon}

The Melomas tree flowers eight times a year. Sometimes the flowering could be induced by pruning or by booster spraying. Unfortunately, there is too much flowering after the induction and the flowers start to drop off, followed by the fruit buds. Apart from physiological problems and nutrition, this could be caused by the abscission of buds or the Anthracnose disease (Figure 1), which is caused by the Collectotrichum acutatum fungus. The symptoms of this disease could be seen are when petals and buds become brown and black as a result of this fungal infection. Buds and fruits will fall to the ground and leaving only the sheath of the stalk. This occurs when the flowering season coincides with the rainy season (Figure 2 and 3). Usually the harvesting season is in March, Jun and October as was in 2006, 2007, and 2008, but there are some reported cases of harvesting outside the rainy season, such as in July. Figure 2 shows the Melomas production graph and a fall in Melomas yield starting from 2003 to 2008, except in 2006, whereby a higher than normal yield was recorded.
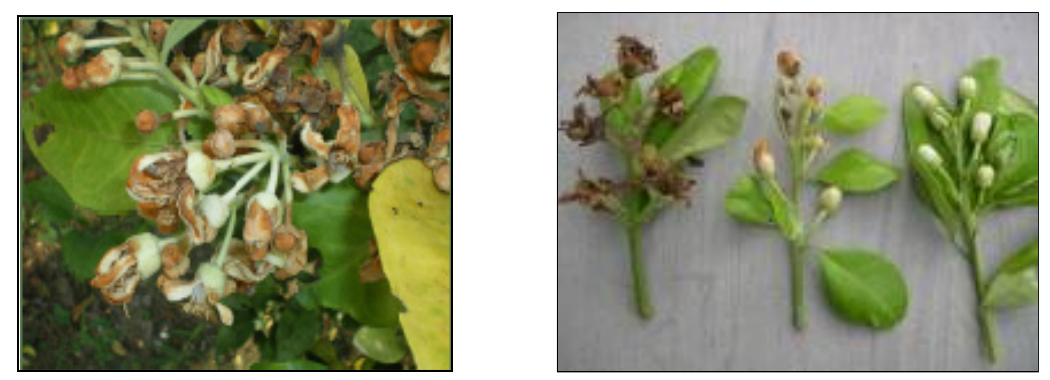

Figure 1. Melomas flowers died during anthesis create yield loses (left), phases of flower infected by fungus (right) 


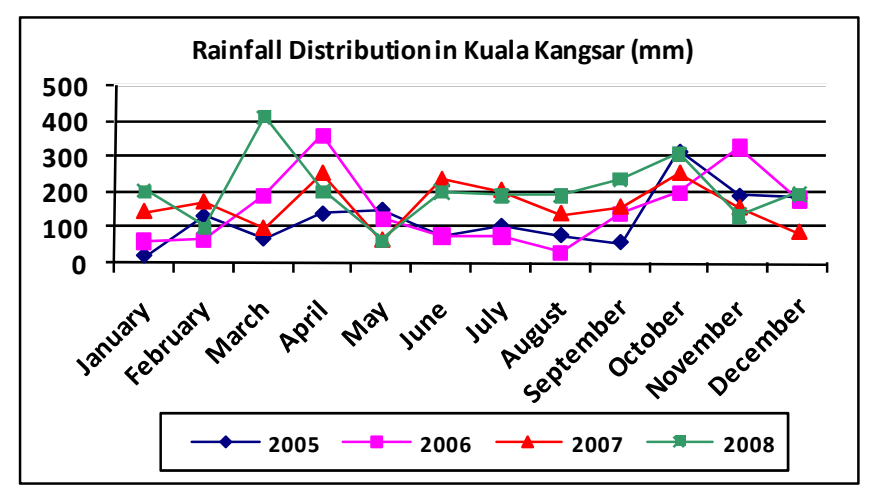

Figure 2. Rainfall distribution in Kuala Kangsar from 2005 to 2008

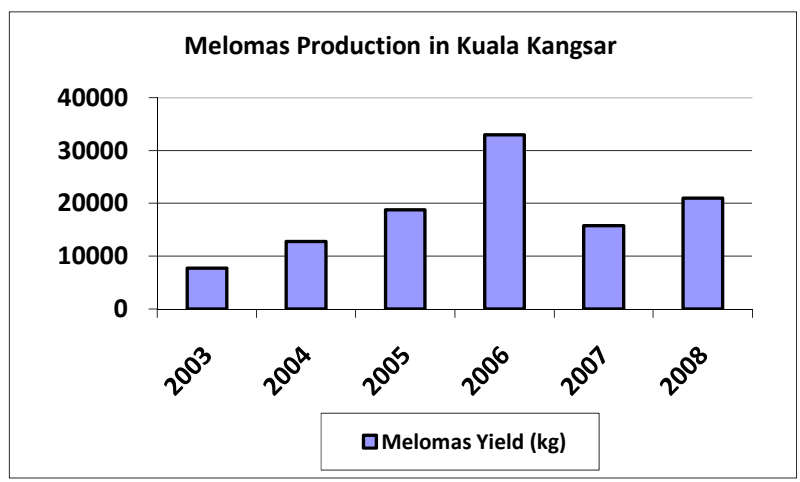

Figure 3. Melomas production from 2003 to 2008

\subsection{Development of Technology through Improved Farm Practices}

The fungal infection problem occurred during the flowering stage of the Melomas clone. Thus, in order to bring this problem under control, the idea of physical intervention to the existing farming practices was introduced. This is to slow down the Anthracnose infection and later managed by fungicide. Some controls had been implemented, such as spraying of fungicides at the flowers and buds. Flowers were sprayed with fungicides such as Amistar or Benlate (other fungicides used were Daconil, Maneb \& Kocide) at least once before anthesis. During anthesis, when the weather is usually humid and rain, the spraying of fungicides is doubled. However, the incidence of infection still persisted although extra fungicide spraying was done and this eventually increased the maintenance's cost.

\subsection{Technology Transfer and Adoption}

Technology is subjective and neutral, and development of technical knowledge is a study of mechanical arts and applied sciences. Technology should seen as a medium for applying new improved methods, additional ways of doing things and expansion of new ideas that are reliable in any condition (Jain \& Triandis, 1990). In addition, Hamilton and Singh (1992) defined technology transfer as the process of movement or transfer of information, technical expertise, and people among technical groups. In general, technology refers to products offered by technology producers (Khalil \& Berman, 1992). From an agricultural perspective, farmers who want to acquire agricultural technology need to possess characteristics such as to be technology savvy and competent, ready to accept technology, knowledgeable and have the ability to maintain the technology after acquiring it (Scott, 1992). Thus, the farmer with these characteristic elements will succeed in the technology adoption process. Ishak (2006) found that a majority of farmers were amenable to accept new technologies made available to them but only if it does not incur costs. In this study, the Melomas farmers were already supplied with the new technology via attending workshops, meetings and discussions at the farm level. 


\section{Materials and Methods}

\subsection{Preparation of Transparent Plastic Sheet Cover}

An experiment was carried out in Padang Rengas and similarly replicated and developed at MARDI Kuala Kangsar, Perak. The experiment intended to examine the effect of microenvironment manipulation by applying the transparent plastic cover (TPC) around the newly developed Melomas flower fruit set. Approximately 40 seven year old Melomas trees ( 1 replication per tree) were used in the experiment. There were two treatments considered, one consisting of TPC for as shading material for the flowers and another as a control treatment, set up with no sheet cover. The construction of each TPC was $30 \mathrm{~cm}$ long, $20 \mathrm{~cm}$ wide and $0.5 \mathrm{~mm}$ in thickness, and cut open on the lower end. Young Melomas flowers were identified and only healthy flowers were selected prior to installation of the TPC sheet. The application techniques require that one side of the plastic sheet be raised and stapled to the branch. The other side was left open to provide channel-like access for pollinating agents. The TPC sheets were stapled onto the branch above the bunch of flowers to form a small half cylinder plastic roofing that prevents raindrops hitting the small flowers. Both treatments were labeled for easy traceability. The sheets was replicated 10 times as each replication has 10 treatments. This study had been designed to prevent raindrops from continuously smearing onto the early fruit sets.

\subsection{Survey on Impact of Technology Application and Extension Services}

This research used a survey method to gauge technology introduced to the farmers. The pilot project and the technology package including the TPC practices had generated vast interest among pomelo growers. The number of farmers that had studied and had practiced this technique included all pomelo farmers in seven villages, which comprised 74 pomelo farmers in Padang Rengas and Kuala Kangsar, spanning over 35 hectares of land respectively. Many of the farmers had been demoralized and demotivated from the previous disease infestation for almost 6 years.

\section{Results and Discussion}

The flowering stage reflects the key success of any pomelo farm and to increase the number of fruit set survivals is by applying the bagging system using the TPC for a critical period of 7-10 days of flower anthesis and another 7-10 days for pollination and formation of the young fruit set. Therefore, at least a maximum of 20 days is required for the flowering phase (Figure 4). Hence, an increase in total number of flowers means higher chances of getting a fruit mass and subsequently a better yield. The results indicated that using TPC could create a conducive weather condition for the Melomas clone fruit set of to grow vigorously. However, growers need to wait for another 5 to 6 months for the fruit set to mature before it could be harvested. In fact, this technology could be applied to other crops that facing the same flower and fruit set problems due to unfavorable weather conditions.

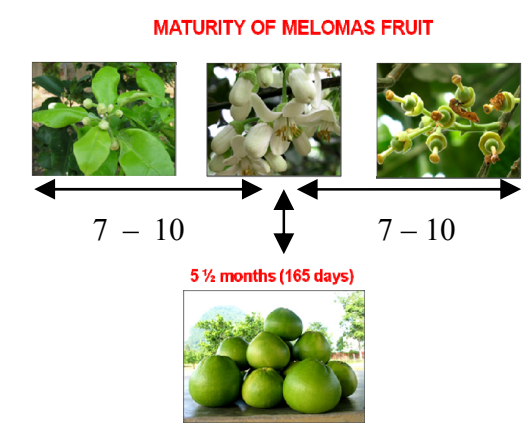

Figure 4. Example of melomas fruit set development

Source: Mohd. Shamsudin et al, 2010.

Hence, the Figure 5 shows the process of TPC application for manipulation of the microenvironment as follows: 


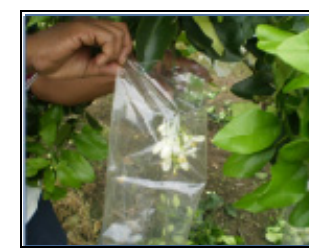

Identify healthy flower newspaper bunch

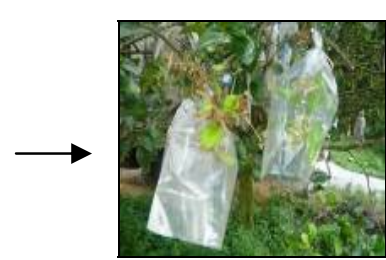

Bagging using transparent plastic cover

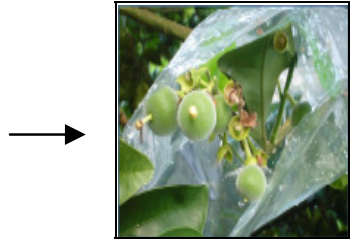

Fruit set development until reach maturity

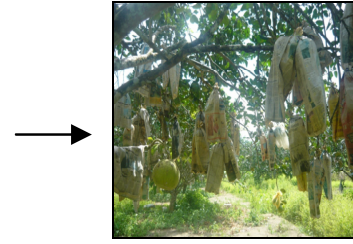

Re-bagging using old to prevent sunlight scorching

Figure 5. Process of TPC application together with fruit set development

It is believed that the occurrence of diseases, especially the Anthracnose had come from raindrops that had triggered the formation of fungus on the flowers and fruit sets. It was observed that this low cost technique had significantly increased the Melomas fruit sets compared to the control (without plastic covers as in Figure 6). The results showed that there was an $85 \%$ success rate of flowering bunches after applying TPC. This technology had been practiced by pomelo farmers in Padang Rengas and $\mathrm{Kg}$. Perlop in $\mathrm{Sg}$. Siput, and in the pilot project in MARDI Kuala Kangsar. It has proven a $72 \%$ increase in farm productivity, able to prompt a healthy flowering phase and increase the yield production in the study area (Figure 7).

The data obtained clearly showed that TPC is a good practice at the farm level. An effective mechanism to solve the surge of sudden diseases using technology transfer had helped improve the yearly performance of Melomas production in the infected areas. The annual production of Melomas after intervention in the project area had increased tremendously from an average of 18,000 kg/year (from 2003 to 2008) to 55,300 kg/year for 2009 (Figure 7). It is notable that the production of Melomas had experienced a two-fold increase in production capacity from year to year since 2010 onwards.

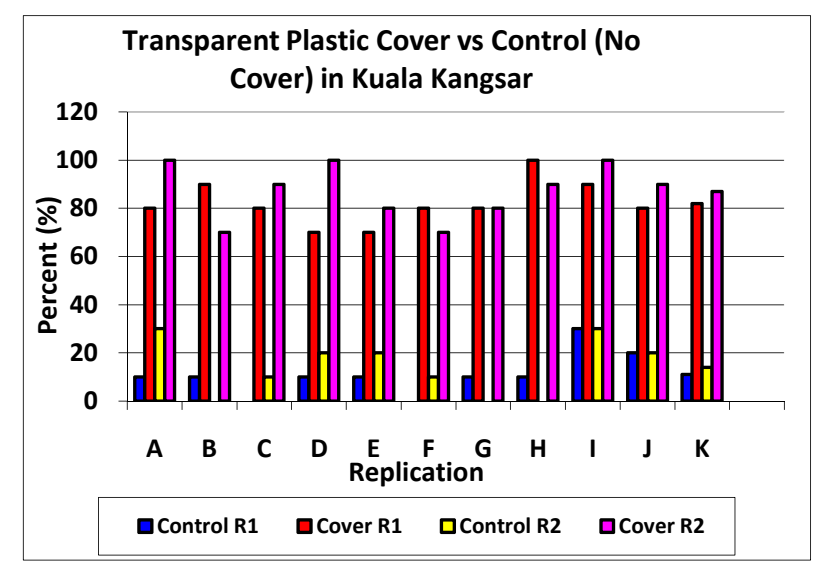

Figure 6. Transparent plastic cover treatment vs control treatment (no cover) 


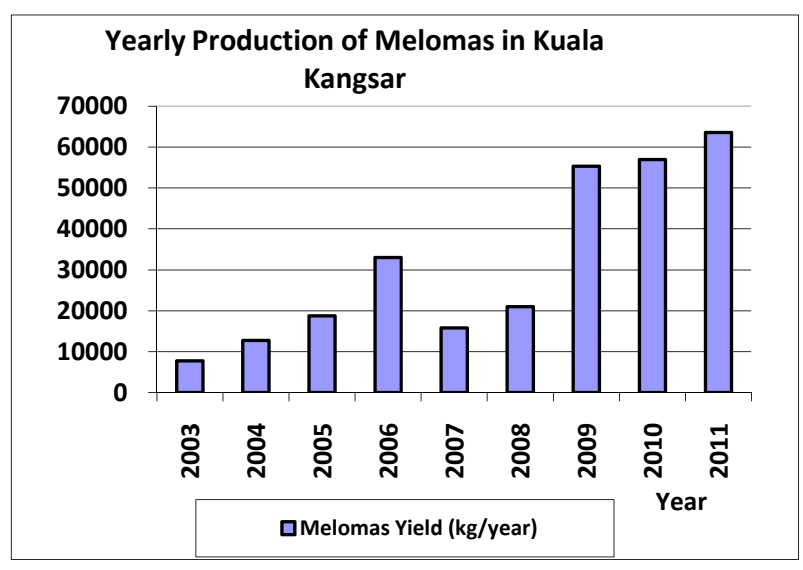

Figure 7. Yearly production of Melomas from 2003 to 2011

Study on the farmer's response showed that awareness of operators had increased significantly (some by 100 percent) after joining the course (Figure 8 and 9). A majority of them said they only realized its seriousness when their farm conditions became severely uncontrollable due to the disease. The results from the survey found that farmers needed motivational support, demonstration on plot gathering, hands-on practical training, workshops on improved technology applications, lectures, discussions and meetings. From the survey done in the area, mechanisms of technology transfer were implemented during public lectures and the farmers appreciated the hands-on practical training given to them. The hands-on training exposed the growers to skills needed to manage their crops by following good agronomic practices. A basic course or workshop session conducted in series had helped farmers gain knowledge and understanding that Melomas needs additional crop care management especially during the flowering stages. Survey has shown that 100 percent of farmers had not applied the TPC practices. After the intervention had taken place, the farm operators became more organized and well prepared as shown by the impressive increase in farm productivity from 50 percent to 85 percent and the flowering success rate elevated from 15 percent to 90 percent (Figure 8 and 9). All aspects of awareness, farm productivity, technology implementation and flowering success had a remarkable rise at the end of the project survey. This intervention had led to numerous multiple success records of farmers' achieving increased pomelo yield performance and income generation.

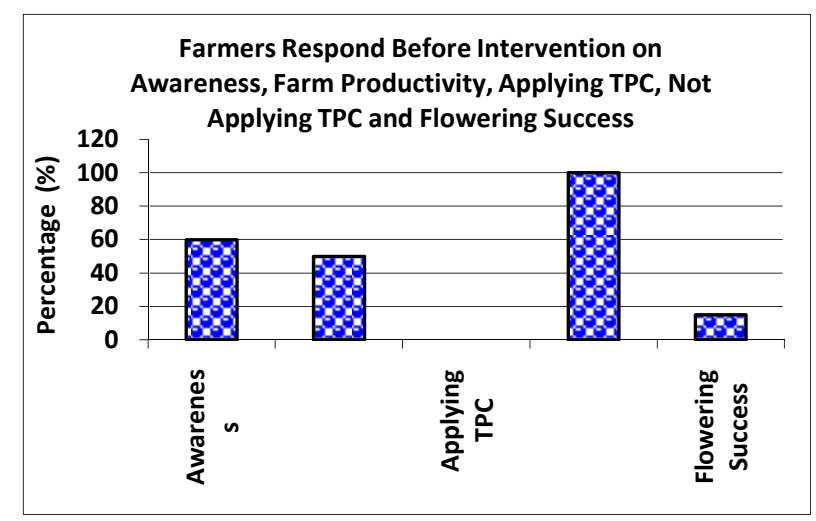

Figure 8. Farmer's response before intervention 


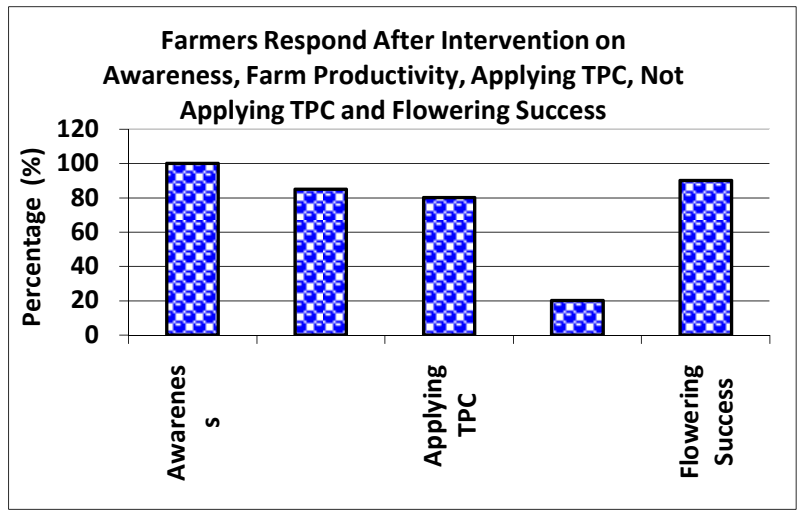

Figure 9. Farmer's response after intervention

\subsection{Role of Extension Agents}

The most important aspect in any rehabilitation process of idle farms is the role of extension agents during the transition period of educating farmers who are less motivated, to become highly motivated farmers. The farmers really need the moral support and assistance from the extension agents that act as the government's frontline officials who undertake initiatives to reduce the burden of these farmers. Based on interviews with the extension educators, they perceive the extension agent's role as a personal gratification and fulfillment of their generous aim to help the farmers achieve their goal. This perception shows that the extension agents already know their role on what needs to be done and what type of problems that needs to be solved in the programs arranged for the farmers. Findings showed that pomelo growers foresee extension agents as their leaders and they obey the instructions given by these agents. Azizan et al. (2011) had found and discussed some of the qualities of an extension agent such as the elements of leadership competency, resourcefulness, problem solving and the ability to capture people's attention.
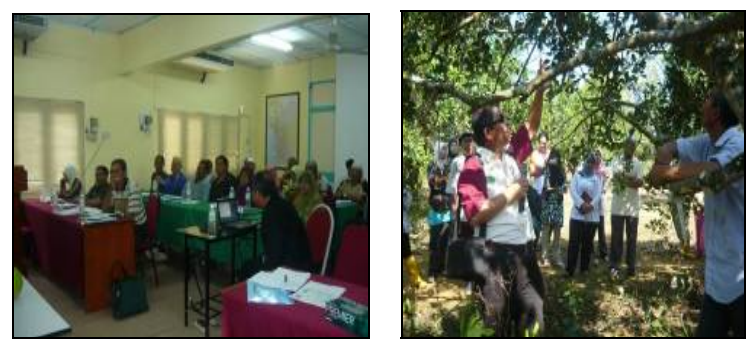

Figure 10. Extension agents giving lectures in Melomas workshop (left) and hands-on training (right)

From random interviews with farmers, it was found that there were numerous ways of facilitation and methods that could help them change. From field observations, few of the farmers did not know how to acquire relevant knowledge or what they want or how to venture independently, but they had the spirit and will to learn what is presented to them. Moreover, a majority of them is willingly to participate in the program and is enthusiastic to improve themselves. This proves that the approach of having programs (like that mentioned earlier) does facilitate the farmers. The connection between farmers and extension agents is seen in the planned change from non-responsive or moderate farmers to active and motivated farmers. The majority of farmers agreed that all the planned programs had helped them to become more responsive and aware of the importance of crop care practices with updated technology applications such as the usage of TPC to increase flowering success rate and preventing the reoccurrence fungal diseases.

\section{Conclusion}

Clearly, the objectives of this study have been met. This report presents an approach to rehabilitate idle pomelo farms through intervention by manipulation of the microenvironment at the flowering stage by applying TPC, intervention of agricultural extension services and promoting change in their farm. A low-cost technique like TPC 
is an easy, money saving application and benefits the majority of farmers in Kuala Kangsar within a short period. Although the TPC practice in reality is simple but the impact has been far-reaching and very effective in rejuvenating the Melomas harvest in Kuala Kangsar and making Kuala Kangsar one of the major areas that contributes to the country's Melomas production. This technology had successfully helped growers to produce good quality, high yielding Melomas. This study also reflects the role of extension agents on their efficiency and competency when confronting issues and solving the farmer's problems.

\section{Acknowledgements}

The authors would like to express appreciation to Mr. Mohd Sulaiman bin Abd Ranie (MARDI Perak), Mr. Wan Mansor bin Wan Ismail (DOA Padang Rengas), Kuala Kangsar Melomas Grower's Association and the MARDI's staff for their assistance \& for providing the facilities during this study.

\section{References}

Azizan, A., Azahari, I., Jasmin, A. S., \& Hayrol, A. M. S. (2011). Competency of agriculture extension officers: the case of paddy development area in Selangor, Malaysia. Paper presented at the Seminar Hasil Penyelidikan IPSAS, Universiti Putra Malaysia.

Sofian, M. S. (2008). Agricultural extansion and sustainable agriculture development in Malaysia-Perspectives and issues. Paper presented at International Conference on Agricultural Extension, Equatorial Hotel, Bangi-Putrajaya.

Fama. (2003). Tinjauan pasaran pertanian dan makanan: Buah-buahan terpilih. Federal Agricultural Marketing Authority (FAMA), Ministry of Agriculture Malaysia.

Hamilton, W., \& Singh, H. (1992). The evolution of corporate capabilities in emerging technologies. Interfaces, 22(4), 13-23. http://dx.doi.org/10.1287/inte.22.4.13

Ibrahim, O. (2000). Business proposal for commercial cultivation of pomelo (Citrus maxima). Hoticulture Research Centre, MARDI.

Ishak, S. (2006). Sejarah socio-budaya Melayu. Karisma Publication Sdn. Bhd., Selangor.

Jain R. K., \& Triandis, H. C. (1990). Management of research and development organisations: managing the unmanageable. In Management Control Systems For R\&D Activities In Government Sector: A Case Of Indonesia. International Review of Business Research Papers, 5(3), 26-33.

Khalil, T., \& Berman, E. M. (1992). Technological competitiveness in the global economy: a survey, International Journal of Technology Management, 7(445), 347-358.

MOA. (2010). Perangkaan Tanaman: Buah-buahan 2010. Department of Agriculture, Ministry of Agriculture and Agro-base Industry, Putrajaya, Malaysia.

Mohd Shamsudin, O., Abdul, R. M., Ibrahim, O., \& Mohd Khairol, M. A. (2010). Manual teknologi penanaman limau bali varieti Melomas. Malaysian Agricultural Research Institute (MARDI), Serdang.

Sinar, H. (2012). Pusat mahu popular kembali Kubang Pasu 'hab' limau bali. Wartawan Berita Sinar Harian, Kuala Lumpur. Retrieved from http://www.sinarharian.com.my/nasional/pusat-mahu-popular-kembali-kubang-pasu-hab-limau-bali-1.1973 1

Scott, M. B. (1992). Behavioral aspects of technology adoption. Journal of Extension, 30(2).

\section{Copyrights}

Copyright for this article is retained by the author(s), with first publication rights granted to the journal.

This is an open-access article distributed under the terms and conditions of the Creative Commons Attribution license (http://creativecommons.org/licenses/by/3.0/). 